\title{
Eggshell Biliverdin and Protoporphyrin Pigments in a Songbird: Are They Derived from Erythrocytes, Blood Plasma, or the Shell Gland?
}

\author{
Rita Hargitai ${ }^{1, *}$ \\ Nóra Boross ${ }^{1}$ \\ Susanne Hámori ${ }^{2}$ \\ Eszter Neuberger ${ }^{2}$ \\ Zoltán Nyiri ${ }^{2}$ \\ ${ }^{1}$ Behavioural Ecology Group, Department of Systematic \\ Zoology and Ecology, Eötvös Loránd University, Pázmány \\ Péter sétány 1/C, H-1117 Budapest, Hungary; ${ }^{2}$ Joint Research \\ and Training Laboratory on Separation Techniques, Eötvös \\ Loránd University, Pázmány Péter sétány 1/A, H-1117 \\ Budapest, Hungary
}

Accepted 8/2/2017; Electronically Published 9/22/2017

\begin{abstract}
Biliverdin and protoporphyrin pigments are deposited into the eggshell when the developing egg is in the shell gland. However, the site of synthesis of eggshell pigments is still uncertain, although it may influence the possible costs and potential functions of eggshell coloration in avian species. Eggshell pigments may be derived from red blood cells or be produced in other organs and then transferred to the shell gland, or they may be synthesized de novo in the shell gland. We studied in the canary (Serinus canaria) whether eggshell blue-green and brown pigmentations are associated with experimentally elevated anemia, female hematocrit level, immature erythrocyte percentage, and feces and plasma pigment levels during egg laying to find out the possible origin of eggshell pigments. We found no significant effects of hematocrit level or experimentally elevated anemia on intensity of eggshell blue-green and brown pigmentations; therefore, we consider it less likely that eggshell pigments are derived from erythrocytes. In addition, we found no significant associations between female feces biliverdin concentration during egg laying and intensity of eggshell blue-green pigmentation, suggesting that eggshell biliverdin may not originate from the spleen or liver. We found a negative association between plasma and feces protoporphyrin concentrations during egg laying and eggshell brown chroma. This result suggests that an increased production of protoporphyrin in the liver, which could have elevated plasma and feces protoporphyrin
\end{abstract}

*Corresponding author; e-mail: rita.hargitai@gmail.com.

Physiological and Biochemical Zoology 90(6):613-626. 2017. (C) 2017 by The University of Chicago. All rights reserved. 1522-2152/2017/9006-16177\$15.00. DOI: $10.1086 / 694297$ concentrations, could inhibit eggshell protoporphyrin pigmentation, probably through affecting enzymatic activities. We suggest that both pigments are produced de novo in the shell gland in the canary, but circulating pigment levels may influence shell gland pigment synthesis, thus connecting the physiological status of the female to eggshell coloration.

Keywords: anemia, antioxidants, bile pigments, eggshell coloration, oxidative stress, sexually selected eggshell coloration hypothesis, shell gland.

\section{Introduction}

Avian eggs show a large variability in coloration and patterns, which has a major genetic basis (Collins 1993; Gosler et al. 2000; Morales et al. 2010). Several hypotheses have been proposed for the possible function of avian eggshell pigmentation (Kilner 2006; Reynolds et al. 2009; Maurer et al. 2011). For example, eggshell pigmentation may provide crypsis against predators (Oniki 1979; Stoddard et al. 2011; Lovell et al. 2013), or it may help parents to identify their eggs in species exposed to brood parasites (Stokke et al. 1999; Soler et al. 2000; Moskát et al. 2008). In addition, it is possible that eggshell pigments filter harmful solar radiation and have thermoregulatory functions (Bakken et al. 1978; Westmoreland et al. 2007) or that they modify the amount and wavelength of light transmitted through the eggshell and thus affect embryonic development (Maurer et al. 2015). Moreover, eggshell pigments may protect the embryo from transshell microbe contamination (Ishikawa et al. 2010; Fargallo et al. 2014), or they may strengthen the structure of the shell (Gosler et al. 2005; García-Navas et al. 2010; Hargitai et al. 2013).

Biliverdin pigment causes the blue-green background coloration of eggshells, while red-brown eggshell maculation is generated by protoporphyrin pigment (Kennedy and Vevers 1976; Mikšík et al. 1996; Gorchein et al. 2009). Biliverdin shows an antioxidant activity toward reactive oxygen species (Stocker et al. 1987; McDonagh 2001; Kaur et al. 2003). In contrast, protoporphyrin possesses prooxidant properties (Afonso et al. 1999; Pimentel et al. 2013). The sexually selected eggshell coloration (SSEC) hypothesis assumes that only high-quality females can afford the costs of depositing large amounts of biliverdin into the eggshell during reproduction, a time of a significant demand for antioxidant compounds (Moreno and Osorno 2003). This hypothesis predicts a positive association between female antioxidant capacity and intensity of eggshell blue-green coloration. 
Support for the condition dependence (Moreno et al. 2006; Siefferman et al. 2006; Duval et al. 2013) and connection to female antioxidant capacity of blue-green eggshell coloration has been found in several avian species (Morales et al. 2011; Butler and McGraw 2013; Hargitai et al. 2016a).

Regarding the protoporphyrin-based eggshell pigmentation, more intense brown eggshell coloration may reflect the poorer physiological condition and higher level of oxidative stress of the female bird, which may induce her to remove large quantities of this prooxidant from her body to reduce oxidative damage (Moreno and Osorno 2003). The hypothesis that darker brown eggshell pigmentation is associated with poorer maternal condition has been supported by the findings of several previous studies (Martínez-de la Puente et al. 2007; Stoddard et al. 2012; Duval et al. 2013; Hargitai et al. 2016a, 2016b).

The origin of eggshell pigments has been extensively studied in domestic poultry. It has been recognized that pigments are deposited into the eggshell when the developing egg spends ca. $20 \mathrm{~h}$ in the shell gland (uterus; Poole 1967; Baird et al. 1975; Soh et al. 1993). However, the site of synthesis of eggshell pigments is still uncertain. First, it has been suggested that damaged and aging erythrocytes could be engulfed by macrophages in the shell gland (Kennedy and Vevers 1973), and heme could then be oxidized to biliverdin or converted to protoporphyrin by substituting $\mathrm{Fe}^{2+}$ for $\mathrm{H}^{+}$(Wang et al. 2009). Zhao et al. (2006) found that the level of biliverdin in serum, bile, and feces did not differ between blue- and brown-shelled chickens, but biliverdin concentration in the shell gland was significantly higher in blue- than in brown-shelled chickens. In addition, heme-oxygenase (HO) gene expression and enzyme activity in the shell gland was significantly higher in blue- than in brown-shelled chickens (Wang et al. 2011). In contrast, in the spleen and liver, HO enzyme gene expression and activity showed no significant difference between blue- and brown-shelled chickens, suggesting that the origin of eggshell biliverdin is not the spleen or liver (Wang et al. 2013). These results suggest that eggshell biliverdin pigment is most likely synthesized in the shell gland by heme oxidation, although it is not clear whether heme is derived from circulating red blood cells or is produced de novo in the cells of the shell gland.

Second, it is possible that biliverdin and protoporphyrin pigments, synthesized in other organs outside the shell gland and circulating in the bloodstream, are absorbed by the cells in the shell gland and then deposited into the eggshell. Biliverdin is synthesized mainly in the spleen but also in the liver and bone marrow, where aging and damaged erythrocytes are removed from the circulation by the phagocytic activity of macrophages (Murray 2003). Within these cells, heme is oxidized to biliverdin, which is the predominant end product of heme degradation in birds in contrast to mammals, who reduce biliverdin to bilirubin (Maines 1988; Murray 2003; Kikuchi et al. 2005). Biliverdin is released into the circulation and is transferred to the liver bound to serum albumin (Lamola et al. 1981; Murray 2003). From the liver, biliverdin is excreted via the bile into the intestine, and then it leaves the body in the feces (Murray 2003). Protoporphyrin is produced during the process of heme synthesis mainly in the hepatocytes of the liver and in the differentiating erythrocytes in the bone marrow (Murray 2003). During the synthesis, gamma-aminolevulinic acid (dALA) is generated from glycine and succinyl-coenzyme A by the enzyme ALA synthase (Murray 2003). Next, dALA is converted to porphobilinogen by the enzyme ALA dehydratase, and porphobilinogen is converted to protoporphyrin through several further steps (Murray 2003). Finally, ferrochelatase enzyme catalyzes the conversion of protoporphyrin into heme (Murray 2003). The rate-limiting enzyme responsible for this reaction, ALA synthase, is negatively regulated by heme concentration in nonerythroid cells (Murray 2003). Limitation in iron availability could inhibit the conversion of protoporphyrin into heme, and therefore the level of protoporphyrin in the circulation and in the feces increases (Langer et al. 1972; Piomelli et al. 1975). Protoporphyrin in the blood can also be carried to the liver, from where it is excreted via the bile together with biliverdin (Lamola et al. 1981; Murray 2003).

Third, some studies on poultry support the idea that the origin of eggshell pigments is the shell gland, where protoporphyrin is synthesized de novo via the dALA pathway. Ferrochelatase enzyme, which catalyzes the conversion of protoporphyrin into heme, could be inhibited in this process. Polin (1957) reported that the tissue of the shell gland of chickens produced significantly more porphyrins compared to liver tissue in vitro. It was reported that levels of ALA synthase and ALA dehydratase were significantly higher, while ferrochelatase activity was lower in the uterus of brown- than of whiteshelled chickens (Stevens et al. 1974; Schwartz et al. 1980). In the Japanese quail (Coturnix japonica), ALA dehydratase enzyme activity was higher during the pigmentation process in the shell gland than in the liver (Yamada 1972), and ALA dehydratase activity increased slightly when an egg was present in the oviduct (Stevens et al. 1974). Similarly, biliverdin could be produced in the shell gland if the produced protoporphyrin is converted to heme, which is then oxidized to biliverdin.

It has been assumed by Moreno and Osorno (2003) that allocating biliverdin pigments to the eggshell is costly for the female, as they remove an important antioxidant from their body in a time of need for antioxidants. This hypothesis assumes that allocating biliverdin into the eggshell necessarily reduces its availability in the circulation, and the circulating biliverdin level positively correlates with plasma antioxidant capacity. Nevertheless, to date, no study has tested this assumption, although the possible costs of eggshell pigmentation for the female could differ depending on the origin of eggshell pigments. For example, if eggshell pigments are derived from aging erythrocytes or are synthesized in the shell gland, we do not expect that the allocation of biliverdin into the eggshell would lower its availability in the circulation and thus compromise the general antioxidant status of the female bird as hypothesized by Moreno and Osorno (2003). In addition, availability of biliverdin in the blood is probably not limited, as biliverdin is continuously produced during the catabolism of heme of aged erythrocytes in the spleen and released into circulation (Murray 2003). However, production of biliverdin could entail costs even when it is synthesized in the shell gland, such as regulation of gene expression and synthesis of enzymes 
and carrier proteins involved in the process, as well as synthesis and secretion of steroid hormones that stimulate pigment accumulation in the shell gland (Yamada 1972; Soh and Koga 1994, 1997), which may all influence the oxidative status of the female.

Here, we experimentally studied the possible origin of biliverdin- and protoporphyrin-based eggshell pigmentation of domestic canaries (Serinus canaria). The canary is an ideal model species for this study because it lays eggs that vary in intensity of both blue-green and brown coloration, it can be easily kept and bred in captivity, and it has a different evolutionary history than the species studied so far (chickens, ducks; e.g., Zhao et al. 2006; Liu et al. 2010; Wang et al. 2013). It is important to distinguish biliverdin- and protoporphyrinbased pigmentation, as the mechanisms determining them are not necessarily the same. Eggshell structure differs between nonpasserines and passerines (Board and Sparks 1991), and it is possible that the mechanism of pigmentation process also differs. To our knowledge, studies regarding the site of eggshell pigment synthesis were conducted within the group Galloanserae (chickens, ducks; Hackett et al. 2008), but no studies were performed within the group Neoaves (modern birds), although most studies investigating the possible behavioral, physiological, and mechanical functions of bird eggshell pigmentation used modern bird species as models. Therefore, studies investigating the physiological mechanisms and site of pigment synthesis of several taxonomic groups of living birds are needed. We examined whether eggshell blue-green and brown pigmentations are associated with experimentally elevated anemia, female hematocrit level, feces and plasma pigment levels, and polychromatophilic erythrocyte (immature red blood cell) percentage during egg laying to find out the possible origin of eggshell pigments. We also aimed to study whether plasma biliverdin and protoporphyrin levels are correlated with plasma antioxidant capacity and the level of oxidative damage to investigate whether maternal oxidative status could be connected to the pigment level in the circulation. To the best of our knowledge, this study is the first that examines the possible origin of eggshell pigments in a songbird.

There may be three different possible origins of eggshell pigments: (1) macrophages in the shell gland may engulf erythrocytes and convert the heme into the pigments, (2) pigments may be synthesized out of the shell gland (in the spleen, liver, bone marrow, or circulating immature erythrocytes) and then absorbed from the circulation by the cells of the shell gland, or (3) pigments may be synthesized de novo in the cells of the shell gland via the dALA pathway. In the first case, we predict a positive association between female hematocrit level during egg laying and intensity of eggshell blue-green and brown pigmentations, and we expect that experimentally induced anemia would cause a reduction in eggshell pigmentation intensity due to the loss of a large number of red blood cells. In the second case, we expect a positive relationship between immature red blood cell percentage (representing red blood cell-producing activity of the bone marrow), plasma pigment level, feces pigment level during egg laying, and intensity of eggshell blue-green and brown pigmentations. We predict that anemia would increase the inten- sity of brown eggshell coloration, as anemia stimulates erythropoiesis (Campbell and Ellis 2013), which could lead to elevated plasma and feces protoporphyrin levels (Langer et al. 1972; Piomelli et al. 1975). In the third case, we expect no positive associations between female hematocrit level, immature red blood cell percentage, and plasma pigment level during egg laying and intensity of eggshell blue-green and brown pigmentations, and we do not expect a significant effect of experimentally induced anemia on eggshell pigmentation.

\section{Material and Methods}

\section{Animals and Housing Conditions}

The experiment was conducted with 1-3-yr-old common domesticated canaries obtained from commercial breeders, and it was performed at Eötvös Loránd University, Budapest, Hungary, from May to June 2014. Birds were kept under natural light conditions supplemented with artificial light in a light cycle of 13L:11D, which allows reproductive behavior. The birds were kept at $23^{\circ} \mathrm{C}$ during breeding. All birds were maintained on a standard-quality diet for canaries (a mixture of grains: 60\% canary grass seed, $12 \%$ flax seed, $10 \%$ hulled oats, $7 \%$ rape seed, $6 \%$ niger seed, 5\% hemp seed; DaCapo Züchter Spezial; Hesa, Himburg, Germany), from which they were given ca. $4 \mathrm{~g}$ per day, supplemented with vegetables. Water, cuttlefish bone, and grit were provided ad lib.

All females were identified with a numbered ring and kept in individual wire cages $(45 \mathrm{~cm} \times 27 \mathrm{~cm} \times 43 \mathrm{~cm})$. Males were individually kept out of the breeding period (cage size: $40 \mathrm{~cm} \times 25 \mathrm{~cm} \times 32 \mathrm{~cm}$ ) but shared the cage of a female during breeding. Cages were equipped with perches and a bath box. Each cage was visually separated from its neighbors by a pasteboard sheet, but birds were in acoustic contact with each other. We studied the second clutches of canaries in the given breeding season. Birds were also included in a previous breeding experiment (Hargitai et al. 2016a), in which control birds of this experiment received antioxidant supplementation and 31-51 d (mean: $42 \mathrm{~d}$ ) elapsed between the termination of the supplementation and the beginning of this experiment. The National Food Chain Safety Office (NÉBIH) provided permissions for this study (PEI/001/ 824-4/2015).

\section{Experimental Design}

Females were weighed with a Pesola spring balance (to the nearest $0.1 \mathrm{~g}$ ), and the length of their tarsus was measured with a pair of callipers (to the nearest $0.1 \mathrm{~mm}$ ) before the start of the experimental treatment. Females had plumage of various colors (yellow, pink, red, brownish gray, melanized green). Females were assigned to one of the two groups (14 treated and 14 control birds) so that the average body mass, tarsus length, distribution of age, and plumage color categories were similar in the two groups. The cages of treated and control females were placed next to each other to avoid any effect of the cage location. 
In the treated group, blood samples $(50-100 \mu \mathrm{L})$ were taken from females every $3 \mathrm{~d}$ before the male was introduced and then every $4 \mathrm{~d}$ until egg laying began. Blood was taken four to seven times during a period of 12-22 $\mathrm{d}$ before egg laying began. Then, blood was taken from both groups during or near egg laying (on the day of laying the third egg: $n=13$ nests; $2 \mathrm{~d}$ after clutch completion: $n=3$ nests; $3 \mathrm{~d}$ after clutch completion: $n=8$ nests; we refer to these periods as "during egg laying"). Blood samples were collected generally between 11:00 a.m. and 1:00 p.m., and blood smears were prepared as well. Blood samples were collected into heparinized capillaries, which were kept chilled until they were centrifuged (usually within $3 \mathrm{~h}$ ) with $10,000 \mathrm{~g}$ for $10 \mathrm{~min}$. There was one blood sample that hemolyzed, but excluding this data point from the statistical models did not change our conclusions (results not shown).

Plasma was separated and stored at $-80^{\circ} \mathrm{C}$. Hematocrit was measured following centrifugation with a ruler (to the nearest $0.5 \mathrm{~mm}$ ), and it was calculated as capillary length occupied by red blood cells divided by capillary length occupied by total blood. In both groups, fresh feces samples were collected by putting a nylon bag to the cage floor for $1-2 \mathrm{~h}$, during which time only the female was in the cage, and then the feces was collected from the nylon bag into Eppendorf tubes. Feces was collected on average $4.1 \pm 2.4 \mathrm{~d}$ (range: 1-10 d) before egg laying began and during egg laying (see above) and was stored at $-80^{\circ} \mathrm{C}$ until later analysis.

After the fourth blood-sampling event in the treated group (after $10 \mathrm{~d}$ from the first blood sampling), a woven wicker nest pan with felt liner and nesting material were provided, and a male bird was placed in the cage. After the male was introduced, we gave $2 \mathrm{~g}$ of grated egg white to all females every $2 \mathrm{~d}$. Cages were checked daily to determine the initiation of egg laying and the exact laying order of the eggs. The laying date did not differ between the treated and the control females $(t=0.80$, df $=22, P=0.43)$. Pair encounters were finished when the clutch was complete. Females laid clutches of one to four eggs (one egg: $n=8$ nests; two eggs: $n=3$ nests; three eggs: $n=6$ nests; four eggs: $n=7$ nests). Clutch size did not differ between the two groups $(t=-0.16, \mathrm{df}=22, P=0.87)$.

Eggs were numbered with a waterproof marker according to laying order, and they were collected on the day of laying. Collected eggs were temporarily replaced by plastic dummy eggs, which had similar size and appearance to canary eggs. Eggs were measured with a spectrophotometer (see below) on the day of laying, and one egg per clutch $(n=9$ first-laid eggs and $n=15$ second-laid eggs) was collected for later eggshell pigmentation analyses. Eggshells of opened eggs were rinsed with tap water, drained, and allowed to dry in room temperature. Eggshells were then put into a microwave oven for 5 min to dry them before weighing and were stored at $-20^{\circ} \mathrm{C}$ in the dark until later analyses.

\section{Eggshell Spectrophotometric Analysis}

Eggshell color was measured using a portable USB4000 spectrometer (Ocean Optics, Largo, FL) with a bifurcated fiberoptic probe (QR400-7-SR-BX; Ocean Optics) and a DH-2000 deuterium-halogen light source (Ocean Optics) on three background and three spotted areas. We used OOIBase 32 software (Ocean Optics) to record the reflectance spectra. The sampling optic was held perpendicular and at a distance of $3 \mathrm{~mm}$ from the eggshell surface. Reference calibration was performed with a white WS-1-SS diffuse reflectance standard (Ocean Optics) after every egg. We calculated blue-green chroma as $\left(R_{480 \mathrm{~nm}}-\right.$ $\left.R_{370 \mathrm{~nm}}\right) / R_{480 \mathrm{~nm}}$, because the eggshell spectra showed peak reflectance at $480 \mathrm{~nm}$ and lowest reflectance at $370 \mathrm{~nm}$ (Hargitai et al. 2016a), which corresponds to the absorption spectra of biliverdin (Singleton and Laster 1965). This calculation method $\left(R_{\max }-R_{\min }\right) / R_{\max }$ is also frequently applied for the carotenoidbased yellow chroma of plumage (Johnsen et al. 2003; Peters et al. 2008) and was also applied in a previous study on canary eggshell coloration (Hargitai et al. 2016a). Brown chroma was calculated as $R_{600-700 \mathrm{~nm}} / R_{320-700 \mathrm{~nm}}$, as protoporphyrin reflects the light at this spectrum region (König and Meyer 1992), while biliverdin has a reflectance minimum around $660 \mathrm{~nm}$ (Singleton and Laster 1965). Therefore, a higher level of the ratio $R_{600-700 \mathrm{~nm}} /$ $R_{320-700 \mathrm{~nm}}$ indicates more protoporphyrin pigment in the eggshell. Spots were selected that were large enough to be measured by the probe of the spectrophotometer. Mean values were calculated by averaging the measurements of three background and three spot areas (Hargitai et al. 2016a).

\section{Eggshell Pigment Analysis}

Biliverdin and protoporphyrin pigment concentrations were determined from one eggshell per clutch. Eggshell samples were weighed and then ground in an agate mortar for 2-3 min until the eggshell became a fine powder. Then, ca. $0.01 \mathrm{~g}$ of the ground eggshell (representing ca. $10 \%$ of the whole eggshell) was put into a centrifuge tube. We used two samples from one eggshell: one (normal) solubilized by adding $750 \mu \mathrm{L}$ of formic acid and $13.3 \mu \mathrm{L}$ of dimethyl sulfoxide and the other (spiked) solubilized by adding $750 \mu \mathrm{L}$ of formic acid and $13.3 \mu \mathrm{L}$ of $100-\mu \mathrm{g} / \mathrm{mL}$ standard (biliverdin-hydrochloride and protoporphyrin) solution in dimethyl sulfoxide. In later analyses, we followed the same steps with both samples. Samples were sonicated for $10 \mathrm{~min}$. Then, eggshell proteins were precipitated by adding $1.24 \mathrm{~mL}$ of ethyl acetate and vortexing for $30 \mathrm{~s}$. The samples were then centrifuged for $5 \mathrm{~min}$ at 5,500 rpm. A $1.5-\mathrm{mL}$ aliquot of the resulting supernatant (ethyl acetate and formic acid) was evaporated under a gentle stream of nitrogen. The residue was redissolved in $190 \mu \mathrm{L}$ of dimethyl sulfoxide. After vortex shaking for $30 \mathrm{~s}$, the samples were transferred into a $1.5-\mathrm{mL}$ autosampler vial.

Reversed-phase high-performance liquid chromatography was performed using an HP 1050 system (Hewlett-Packard, Palo Alto, CA), which was controlled using ChemStation A10.02 software (Agilent, Santa Clara, CA), with an Agilent Eclipse XDB-C18 liquid chromatography column (100 mm $\times$ $4.6 \mathrm{~mm}, 3.5 \mu \mathrm{m})$. A $5-\mu \mathrm{L}$ sample was injected onto the column and eluted with a gradient starting at $60 \%$ for $0.05 \%(\mathrm{v} / \mathrm{v})$ trifluoroacetic acid in Direct-Q water (eluent A) and $40 \%$ for acetonitrile (eluent B). This composition was kept for $0.2 \mathrm{~min}$, 
after which it was changed to $100 \% \mathrm{~B}$ in $4.8 \mathrm{~min}$. This final composition was maintained for $2.5 \mathrm{~min}$. The flow rate was $1.0 \mathrm{~mL} / \mathrm{min}$, and the column was held at $50^{\circ} \mathrm{C}$. The detection wavelength was $384 \mathrm{~nm}$ for the first $5 \mathrm{~min}$ (for biliverdin) and $400 \mathrm{~nm}$ afterward (for protoporphyrin). Peaks were identified and quantified by comparisons with retention times and peak areas of reference materials (biliverdin-hydrochloride and protoporphyrin; Frontier Scientific, Logan, UT). The results are expressed as micrograms per gram of eggshell.

\section{Plasma OXY Test}

Total plasma antioxidant capacity was measured by the OXYadsorbent test (Diacron, Grosseto, Italy) within 4 mo of blood collection, during which storage period no considerable reduction in OXY level is expected (Hargitai et al. 2016c). The OXY test measures the ability of the antioxidant compounds of the plasma (e.g., carotenoids; vitamins A, C, and E; proteins; thiols) to cope with the oxidizing action of hypochlorous acid ( $\mathrm{HOCl})$. First, $2 \mu \mathrm{L}$ of plasma was diluted 1:100 with distilled water. Then, $200 \mu \mathrm{L}$ of $\mathrm{HOCl}$ solution was pipetted into the wells of a microplate and $2 \mu \mathrm{L}$ of the diluted samples was added to each well. The microplate was then incubated at $37^{\circ} \mathrm{C}$ for $10 \mathrm{~min}$ with continuous shaking of medium intensity. After that, $2 \mu \mathrm{L}$ of a chromogenic mixture was added to the wells. The alkyl-substituted aromatic amine solubilized in the chromogen was oxidized by the residual $\mathrm{HOCl}$ of the solution and thus transformed into a pink derivative. Accordingly, the intensity of the pink color was inversely related to the total antioxidant capacity of the plasma. After 5 min of shaking, the absorbance was read by a spectrophotometer (BioTek ELX808 with Gen5 software) at $540 \mathrm{~nm}$. Absorbances were compared to those of a dilution series of a calibrator (stabilized protein solution). Samples were tested in duplicates (mean intra-assay coefficient of variation $[\mathrm{CV}]$ of plasma samples $=1.7 \%$; intraassay repeatability of plasma samples: $r=0.99, F_{81,82}=182.13$, $P<0.001$; interassay repeatability of calibrators: $r=0.33$, $F_{2,72}=13.50, P<0.001$; Lessells and Boag 1987), and results were expressed as millimolars $\mathrm{HOCl}$ neutralized.

\section{Plasma ROM Test}

We measured the plasma level of reactive oxygen metabolites (ROMs, primarily hydroperoxides $[\mathrm{ROOH}]$ ) by the d-ROM assay (Diacron), which is a reliable assay for the quantification of plasma oxidative damage (Costantini 2016). ROMs are intermediate oxidative damage compounds, which are generated by the peroxidation of biological macromolecules (lipids, proteins, nucleic acids) by reactive oxygen species (Halliwell and Gutteridge 2007). Plasma samples were analyzed within 2 mo of blood collection. First, we mixed the reagents (chromogenic mixture [aromatic alkyl-amine] and acetate buffer) in a 1:100 ratio and added $200 \mu \mathrm{L}$ of this solution to Eppendorf tubes; we added $5 \mu \mathrm{L}$ of plasma to the reagent mix in the Eppendorf tubes. Samples were then incubated in a water bath at $37^{\circ} \mathrm{C}$ for $75 \mathrm{~min}$ with shaking. Iron and copper ions are released from plasma proteins in the presence of the acidic buffer, and alkoxyl and peroxyl radicals are generated from hydroperoxides. These highly reactive prooxidant compounds oxidize the aromatic alkyl-amine and transform it into a pink derivative. Thus, the intensity of the pink color is directly proportional to the concentration of ROMs in the sample. Precipitates (lipids, proteins) were present in the solution, so all samples were centrifuged for $2 \mathrm{~min}$ at 10,000 rpm after incubation, including the calibrator and the blank. Then, $190 \mu \mathrm{L}$ of the clear solution was transferred to the wells of a microplate. Absorption was read immediately with a microplate spectrophotometer (BioTek ELX808 with Gen5 software) at $490 \mathrm{~nm}$ and compared to those of a dilution series of a calibrator (lyophilized serum). We did not use duplicates, as the CV of the samples was very low (mean intra-assay CV of plasma samples of great tits [Parus major] analyzed by the same protocol $=2.4 \%$; see also Iamele et al. 2002; intra-assay repeatability of plasma samples of great tits analyzed by the same protocol: $r=0.97$, $F_{50,51}=72.57, P<0.001$; interassay repeatability of calibrators: $r=0.99, F_{2,36}=1,456.3, P<0.001$; Lessells and Boag 1987). Plasma ROM concentration is expressed as millimolars of hydrogen peroxide equivalents.

\section{Plasma Pigment Analysis}

A Waters Alliance 2695 high-performance liquid chromatograph (Waters, Milford, MA) equipped with a Cortecs C18 $4.6 \times 100-\mathrm{mm}, 2.7-\mu \mathrm{m}$ column (Waters) and an inline filter of $2 \mu \mathrm{m}$ diameter was used for the determination of plasma biliverdin and protoporphyrin concentrations. Data acquisition and evaluation were performed using Empower 2 software. First, $10 \mu \mathrm{L}$ of plasma was mixed with $990 \mu \mathrm{L}$ of ethyl acetate containing $0.1 \%(\mathrm{v} / \mathrm{v})$ trifluoroacetic acid and $10 \mu \mathrm{L}$ of dimethyl sulfoxide. The mixture was vortexed for $5 \mathrm{~s}$ and centrifuged for $5 \mathrm{~min}$ at $10,000 \mathrm{rpm}$. Then, the ethyl acetate was evaporated under a gentle stream of nitrogen. The residue was redissolved in $190 \mu \mathrm{L}$ of dimethyl sulfoxide. After vortex shaking for $10 \mathrm{~s}$, the samples were transferred into a $1.5-\mathrm{mL}$ amber glass vial with a $200-\mu \mathrm{L}$ insert for chromatographic measurement. For the determination of the target compounds, a gradient elution was used with a flow rate of $1 \mathrm{~mL} / \mathrm{min}$. The initial composition was $70 \%$ MilliQ water containing $0.1 \%(\mathrm{v} / \mathrm{v})$ trifluoroacetic acid (eluent $\mathrm{A}$ ) and $30 \%$ acetonitrile containing $0.1 \%(\mathrm{v} / \mathrm{v})$ trifluoroacetic acid (eluent B). This composition was kept for 2 min and was then increased to $95 \%$ eluent B in 6 min with a linear gradient. This final composition was maintained for $2 \mathrm{~min}$. The column was held at $50^{\circ} \mathrm{C}$. Protoporphyrin fluorescence was measured at excitation and emission wavelengths of 394 and $598 \mathrm{~nm}$, while biliverdin was detected at $376 \mathrm{~nm}$ with a photodiode array detector. Injection volume was $20 \mu \mathrm{L}$. The results are expressed as nanograms per milliliter of plasma. Limit of quantification was $20 \mathrm{ng} / \mathrm{mL}$ for protoporphyrin and $1 \mu \mathrm{g} / \mathrm{mL}$ for biliverdin.

\section{Feces Pigment Analysis}

A Waters Alliance 2695 high-performance liquid chromatograph (Waters) equipped with a Zorbax Eclipse Plus C18 4.6 × 100-mm, 
5- $\mu \mathrm{m}$ column (Agilent) and an inline filter of $2 \mu \mathrm{m}$ diameter was used for the determination of feces biliverdin and protoporphyrin concentrations. Data acquisition and evaluation were performed using Empower 2 software. Approximately $0.1 \mathrm{~g}$ of the feces sample was weighed with an analytical balance and dried in a desiccator containing silica gel for $48 \mathrm{~h}$. The one-third of the dried sample was vortexed for $60 \mathrm{~s}$ in a centrifuge tube with $400 \mu \mathrm{L}$ of ethylenediaminetetraacetic acid and $1,000 \mu \mathrm{L}$ of ethyl acetate containing $1 \%$ $(\mathrm{v} / \mathrm{v})$ trifluoroacetic acid. The resulting mixture was sonicated for $10 \mathrm{~min}$ at $45^{\circ} \mathrm{C}$ and then centrifuged for $20 \mathrm{~min}$ at 5,500 rpm. An aliquot of $800 \mu \mathrm{L}$ from the upper phase was transferred into a $4-\mathrm{mL}$ amber glass vial. Another $1,000 \mu \mathrm{L}$ of ethyl acetate containing $1 \%$ $(\mathrm{v} / \mathrm{v})$ trifluoroacetic acid was added to the remaining mixture, and the extraction procedure was repeated. An aliquot of $1,000 \mu \mathrm{L}$ from the upper phase was combined with the previous extract and evaporated to dryness under gentle nitrogen stream at ambient temperature. Then, $250 \mu \mathrm{L}$ of dimethyl sulfoxide was added to the vial and sonicated for $2 \mathrm{~min}$ to facilitate the redissolution of the analytes. Finally, the mixture was transferred into a $1.5-\mathrm{mL}$ amber glass vial with an insert for chromatographic measurement. For the determination of feces protoporphyrin and biliverdin, gradient elution was used with a flow rate of $1 \mathrm{~mL} / \mathrm{min}$. The initial composition was $70 \%$ MilliQ water containing $0.05 \%(\mathrm{v} / \mathrm{v})$ trifluoroacetic acid (eluent $\mathrm{A}$ ) and $30 \%$ acetonitrile (eluent $\mathrm{B}$ ). This composition was maintained for 2 min, after which eluent $B$ was increased to $95 \%$ in 6 min with a linear gradient. This final composition was kept for $2 \mathrm{~min}$. The column was held at $40^{\circ} \mathrm{C}$. Protoporphyrin was measured at a wavelength of $398 \mathrm{~nm}$, while biliverdin was measured at $376 \mathrm{~nm}$. Injection volume was $10 \mu \mathrm{L}$. The results are expressed as micrograms per gram of dry feces.

\section{Blood Smear Analysis}

Blood smears were air-dried and fixed in methanol on the same day of collection and later dyed with Giemsa stain. Polychromatophil erythrocyte (immature red blood cell) percentage was determined in blood smears under a magnification of $\times 1,000$ with oil immersion by the same person (R. Hargitai). Polychromatophils are present in higher numbers during red blood cell production (erythropoiesis; Campbell and Ellis 2013). Polychromatophil number was counted in five fields (ca. 1,000 red blood cells), and the average number of red blood cells per field was also estimated (Wagner et al. 2008b). Polychromatophil erythrocyte percentage reflects the number of immature red blood cells divided by the number of total red blood cells in the observed fields. Seven blood smears were examined twice to determine the intraobserver repeatability of polychromatophil percentage, and it was significantly repeatable $\left(r=0.94, F_{6,7}=31.96, P<0.001\right.$; Lessells and Boag 1987).

\section{Statistical Analyses}

We tested the effect of repeated blood-sampling treatment on female physiological variables (hematocrit level, plasma protoporphyrin concentration, feces biliverdin and protoporphyrin concentration, polychromatophil percentage) during egg laying by Student's $t$-tests. Plasma protoporphyrin concentration and feces biliverdin and protoporphyrin concentrations were log transformed because these variables had right-skewed distributions. We also tested the relationships among female physiological variables during the egg-laying period (hematocrit level, plasma protoporphyrin concentrations, feces protoporphyrin and biliverdin concentrations, polychromatophil percentage, female OXY and ROM levels), including treatment as fixed factor, and its interaction with the predictor variable in general linear models. As the interaction between treatment and the predictor variable was nonsignificant in all cases, we did not report its effects.

We tested the effects of treatment and female physiological variables during egg laying on eggshell coloration by applying a general linear mixed model with cage identity as a random factor and eggshell coloration of the first breeding event and egg-laying order as fixed covariates. Data from females from both groups (control and treated) were used in these analyses. We used two separate models for both eggshell pigmentation variables to avoid collinearity among predictor variables. For eggshell blue-green chroma, we used the following predictor variables: (1) hematocrit level and feces biliverdin concentration and (2) treatment and polychromatophil percentage. For eggshell brown chroma, we used the following predictor variables: (1) hematocrit level and feces protoporphyrin concentration and (2) treatment, polychromatophil percentage, and plasma protoporphyrin concentration.

We also tested the association between the clutch mean of eggshell coloration and the difference in female plasma protoporphyrin and feces biliverdin and protoporphyrin concentrations between the prelaying (last blood sampling before egg laying) and egg-laying (days between the two events: $3-$ $12 \mathrm{~d}$; mean: $6.8 \mathrm{~d}$ ) periods with general linear models. In the first model, the difference in feces biliverdin level between the prelaying and laying periods was the dependent variable and the clutch mean of eggshell average blue-green chroma was the independent variable. In the second model, the difference in feces protoporphyrin level between the prelaying and laying periods was the dependent variable and the clutch mean of eggshell average brown chroma was the independent variable. In the third model, the difference in plasma protoporphyrin level between the prelaying and laying periods was the dependent variable and the clutch mean of eggshell average brown chroma was the independent variable.

In all general linear models, backward stepwise selection procedure was employed, removing nonsignificant variables from the model one by one in decreasing order of $P$. To avoid nonsignificance due to overparameterization, nonsignificant variables were reintroduced to the final model one by one, and these $F$ and $P$ values were presented (Hegyi and Laczi 2015). This method mitigates parameter estimation bias of classical stepwise model selection (Hegyi and Laczi 2015). We calculated standardized effect sizes as $R=$ $\sqrt{\left(F \times \mathrm{df}_{1}\right) /\left(\left(F \times \mathrm{df}_{1}\right)+\mathrm{df}_{2}\right)}($ McNeil et al. 1996). Analyses were performed in STATISTICA 5.5 (StatSoft, Tulsa, OK) and SPSS 19.0 (Chicago). 
Results

Effects of Repeated Blood-Sampling Treatment on Female Physiological Variables

Females that were repeatedly bled had lower hematocrit levels during the egg-laying period as compared to control birds (table 1). However, repeated blood-sampling treatment caused no significant differences in polychromatophil percentage, protoporphyrin concentration in plasma and feces, and biliverdin concentration in feces during the egg-laying period between treated and control females (table 1).

\section{Correlations among Female Physiological Traits}

We found that circulating protoporphyrin concentration was positively related to feces protoporphyrin concentration during egg laying $\left(F_{1,21}=11.08, P=0.003, \beta=0.59\right)$. Feces biliverdin concentration was not related to feces protoporphyrin concentration during egg laying $\left(F_{1,21}=0.24, P=\right.$ 0.63). Hematocrit level during egg laying did not correlate with feces biliverdin concentration $\left(F_{1,20}=0.09, P=0.77\right)$, feces protoporphyrin concentration $\left(F_{1,20}=1.44, P=0.24\right)$, plasma protoporphyrin concentration $\left(F_{1,20}=0.22, P=0.64\right)$, and polychromatophil percentage $\left(F_{1,17}=0.16, P=0.69\right)$ during egg laying. Polychromatophil percentage was not significantly related to plasma protoporphyrin level $\left(F_{1,19}=0.72\right.$, $P=0.41)$.

We found that females with a higher circulating protoporphyrin level had better plasma antioxidant capacity (OXY: $F_{1,22}=8.62, P=0.008, \beta=0.53$; fig. 1 ), but the level of oxidative damage $(\mathrm{ROM})$ was not related to plasma protoporphyrin concentration $\left(F_{1,21}<0.001, P=0.99\right)$. Feces protoporphyrin concentration was unrelated to female plasma OXY level $\left(F_{1,21}=1.62, P=0.22\right)$ and ROM level $\left(F_{1,20}=0.27, P=\right.$ 0.61 ). As the level of biliverdin was below the limit of quantification $(1 \mu \mathrm{g} / \mathrm{mL})$ in the canary plasma, we could not test its associations with OXY and ROM levels. However, we tested the associations between feces biliverdin concentration and female oxidative status, and both relationships were nonsignificant (OXY: $F_{1,22}=0.14, P=0.71$; ROM: $F_{1,21}=1.37, P=0.26$ ).

\section{Eggshell Pigmentation and Female Traits during Egg Laying}

Eggs were laid by 11 control and 13 treated females. Eggshell average blue-green chroma showed a significant positive correlation with eggshell biliverdin concentration $(r=0.55, n=$ $23, P=0.007)$. Eggshell average brown chroma strongly positively correlated with eggshell protoporphyrin concentration ( $r=0.78, n=23, P<0.001)$. Average blue-green chroma and brown chroma were negatively correlated $(r=-0.33, n=59$, $P=0.012$ ).

Eggshell blue-green chroma was unrelated to repeated bloodsampling treatment, female hematocrit level, feces biliverdin concentration, and polychromatophil percentage during egg laying (table 2). Eggshell brown chroma was unrelated to bloodsampling treatment, female hematocrit level, and polychromatophil percentage during egg laying (table 2). We found that plasma (fig. 2) and feces protoporphyrin concentrations (fig. 3) significantly negatively correlated with eggshell brown chroma (table 2). We found a positive correlation in eggshell bluegreen chroma between the first and second clutches (table 2) and in eggshell brown chroma between the first and second clutches (table 2).

In addition, we analyzed whether the change in plasma and feces pigment levels between the prelaying and laying periods were connected to the intensity of eggshell pigmentation, but we found no significant associations for either blue-green eggshell chroma (difference in feces biliverdin level: $F_{1,20}=0.69$, $P=0.42$ ) or brown eggshell chroma (difference in plasma protoporphyrin level: $F_{1,9}=0.02, P=0.90$; difference in feces protoporphyrin level: $F_{1,19}=0.11, P=0.74$ ).

\section{Discussion}

Biliverdin and protoporphyrin pigments are deposited into the eggshell when the egg is in the shell gland (Poole 1967; Baird et al. 1975; Soh et al. 1993), but the site of synthesis of eggshell pigments of passerine birds is not known. Eggshell pigments may be converted from the heme of red blood cells that are engulfed by the cells of the shell gland. In this case, we predicted a positive correlation between female hematocrit

Table 1: Effects of repeated blood-sampling treatment on female physiological variables during egg laying in the canary and the mean and SD values of control and treated groups

\begin{tabular}{|c|c|c|c|c|c|c|c|}
\hline \multirow[b]{2}{*}{ Blood-sampling treatment } & \multirow[b]{2}{*}{$t$} & \multirow[b]{2}{*}{ df } & \multirow[b]{2}{*}{$P$} & \multicolumn{2}{|c|}{ Control group } & \multicolumn{2}{|c|}{ Treated group } \\
\hline & & & & Mean/median & $\mathrm{SD} / \mathrm{QR}$ & Mean/median & $\mathrm{SD} / \mathrm{QR}$ \\
\hline Hematocrit (\%) & 2.88 & 21 & .009 & .43 & .04 & .39 & .03 \\
\hline Feces biliverdin level $(\mu \mathrm{g} / \mathrm{g})$ & .44 & 22 & .66 & $66.33^{\mathrm{a}}$ & $81.03^{\mathrm{a}}$ & $55.93^{\mathrm{a}}$ & $36.60^{\mathrm{a}}$ \\
\hline Feces protoporphyrin level $(\mu \mathrm{g} / \mathrm{g})$ & .31 & 21 & .76 & $5.65^{\mathrm{a}}$ & $5.65^{\mathrm{a}}$ & $4.67^{\mathrm{a}}$ & $2.63^{\mathrm{a}}$ \\
\hline Plasma protoporphyrin level $(\mathrm{ng} / \mathrm{mL})$ & 1.24 & 22 & .23 & $38.49^{\mathrm{a}}$ & $48.41^{\mathrm{a}}$ & $33.58^{\mathrm{a}}$ & $21.50^{\mathrm{a}}$ \\
\hline Polychromatophil erythrocyte (\%) & -.73 & 19 & .47 & 3.41 & 2.04 & 4.09 & 2.17 \\
\hline
\end{tabular}

Note. Plasma protoporphyrin concentration and feces biliverdin and protoporphyrin concentrations were log transformed before statistical analyses, but we present their untransformed median concentration and quartile range (QR) values here. Analyses were performed with Student's $t$-tests.

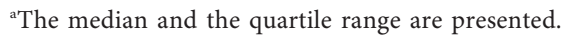




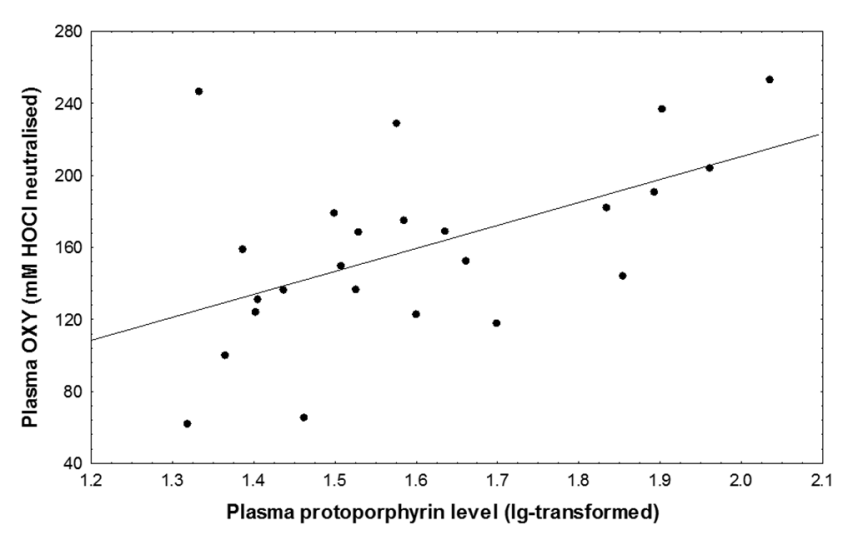

Figure 1. Relationship between female plasma protoporphyrin concentration (ng/mL; lg-transformed) during egg laying and plasma total antioxidant capacity (OXY) in the canary $(\beta=0.53, P=0.008)$.

level and intensity of eggshell blue-green and brown pigmentations, and we expected that treatment would cause a reduction in eggshell pigmentation intensity. It is also possible that pigments are produced in other organs (liver, spleen, bone marrow) and then transferred via the circulation to the shell gland. In this case, we predicted a positive correlation between immature red blood cell percentage, plasma pigment level, feces pigment level, and intensity of eggshell blue-green and brown pigmentations, and we expected that treatment would have a positive effect on eggshell pigmentation as well. More- over, we expected a relationship between the change in circulating and feces pigment levels between the prelaying and laying periods and the intensity of eggshell pigmentation. Third, eggshell pigments may be synthesized de novo in the cells of the shell gland via the dALA pathway. In this case, we predicted no positive correlations between female hematocrit level, immature red blood cell percentage, and plasma pigment level and intensity of eggshell blue-green and brown pigmentations, and we did not expect a significant effect of our treatment on eggshell pigmentation.

\section{Effects of Repeated Blood-Sampling Treatment on Female Physiological Variables}

We found that repeated blood-sampling treatment increased anemia, but it had no significant influence on polychromatophil percentage, suggesting that red blood cell-producing activity of the bone marrow was not elevated. Similarly, plasma and feces levels of protoporphyrin were not increased by our treatment, which could also be related to the lack of increase in immature red blood cell count in the circulation. In the process of erythropoiesis (red blood cell formation), polychromatophil erythrocytes develop and mature in the bone marrow and then circulate for 1-2 $\mathrm{d}$ in the bloodstream before developing into mature red blood cells (Campbell and Ellis 2013). The number of polychromatophil erythrocytes is a good indicator of the red blood cell-formation activity of the bone marrow because it represents recent production. Anemia

Table 2: Relationships between blood-sampling treatment and female physiological variables during egg laying and eggshell average blue-green and brown chroma in the canary

\begin{tabular}{|c|c|c|c|c|}
\hline Chroma and predictor variables & $F$ & df & $P$ & $R$ \\
\hline \multicolumn{5}{|l|}{ Blue-green chroma: } \\
\hline Hematocrit level & .06 & $1,55.00$ & .82 & .03 \\
\hline Feces biliverdin level & .75 & $1,55.00$ & .39 & .12 \\
\hline Egg-laying order & 1.16 & $1,55.00$ & .29 & .14 \\
\hline Blue-green chroma (first breeding) & 4.82 & $1,55.00$ & .032 & .28 \\
\hline \multicolumn{5}{|l|}{ Blue-green chroma: } \\
\hline Blood-sampling treatment & 1.02 & $1,55.00$ & .32 & .13 \\
\hline Polychromatophil percentage & .13 & $1,55.00$ & .72 & -.05 \\
\hline Egg-laying order & .71 & $1,55.00$ & .40 & .11 \\
\hline Blue-green chroma (first breeding) & 7.64 & $1,55.00$ & .008 & .35 \\
\hline \multicolumn{5}{|l|}{ Brown chroma: } \\
\hline Hematocrit level & .001 & $1,17.82$ & .98 & .01 \\
\hline Feces protoporphyrin level & 8.87 & $1,18.22$ & .008 & -.57 \\
\hline Egg-laying order & 1.44 & $1,46.85$ & .24 & -.17 \\
\hline Brown chroma (first breeding) & 4.93 & $1,27.75$ & .035 & .39 \\
\hline \multicolumn{5}{|l|}{ Brown chroma: } \\
\hline Blood-sampling treatment & .37 & $1,55.02$ & .37 & .08 \\
\hline Polychromatophil percentage & .62 & $1,55.01$ & .43 & .11 \\
\hline Plasma protoporphyrin level & 9.75 & $1,55.00$ & .003 & -.39 \\
\hline Egg-laying order & 1.39 & $1,55.01$ & .24 & -.16 \\
\hline Brown chroma (first breeding) & 4.72 & $1,55.00$ & .034 & .28 \\
\hline
\end{tabular}

Note. Analyses were performed with general linear mixed models. Standardized effect sizes were calculated as $R=$ $\sqrt{\left(F \times \mathrm{df}_{1}\right) /\left(\left(F \times \mathrm{df}_{1}\right)+\mathrm{df}_{2}\right)}($ McNeil et al. 1996). 


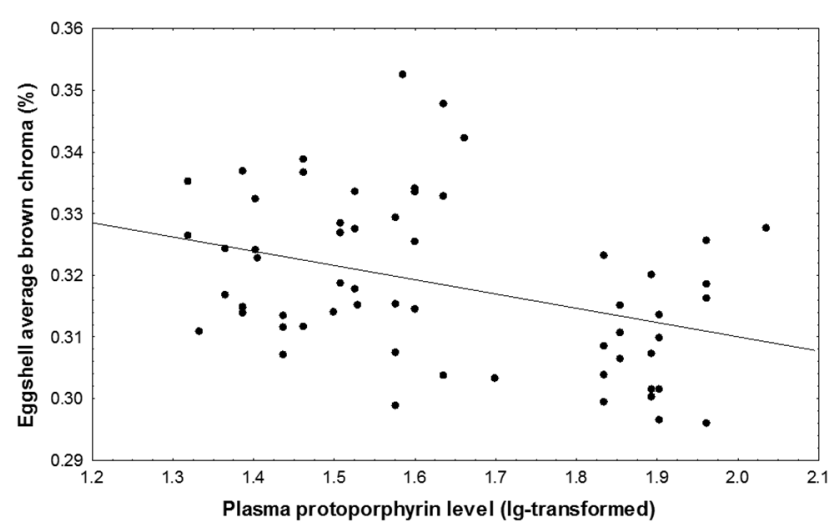

Figure 2. Relationship between female plasma protoporphyrin concentration (ng/mL; lg-transformed) during egg laying and eggshell average brown chroma in the canary $(R=-0.39, P=0.003)$.

generally results in an increased erythropoiesis to compensate for the reduced number of erythrocytes (Campbell and Ellis 2013). In this case, the proportion of polychromatophil erythrocytes (immature red blood cells) often increases (Campbell and Ellis 2013), and this increase generally peaks 4-7 d after the induction of anemia (Fernandez and Grindem 2006). However, it has been proposed that erythropoiesis is transiently suppressed during reproduction, probably through estrogen hormone (Wagner et al. 2008a), and therefore the recovery from anemia is relatively slow (Wagner et al. 2008b; Willie et al. 2010). This transient inhibition could explain why our repeated bleeding treatment did not activate the red blood cell-formation activity in the bone marrow of female birds.

\section{Correlations among Female Physiological Traits}

We found that plasma protoporphyrin concentration was not related to plasma level of oxidative damage of the female, but it showed a positive correlation with plasma antioxidant capacity. A high level of protoporphyrin may stimulate an increase in the capacity of the antioxidant defense system (Afonso et al. 1999), and this could be the reason why plasma protoporphyrin concentration correlated positively with plasma OXY level. We did not find significant relationships of feces protoporphyrin and biliverdin concentrations with plasma oxidative status. In chickens, biliverdin concentration in serum was 3-7 $\mu \mathrm{mol} / \mathrm{L}$ (Zhao et al. 2006), but in the canary, the plasma biliverdin level was lower than the limit of quantification of our method $(<1 \mu \mathrm{g} / \mathrm{mL}=1.7 \mu \mathrm{mol} / \mathrm{mL})$; therefore, we could not test its associations with OXY and ROM levels.

\section{Eggshell Pigmentation and Female Traits during Egg Laying}

We found that repeated bleeding treatment, which elevated anemia and hematocrit level during egg laying, had no significant effects on intensity of eggshell blue-green and brown pigmentations in the canary. The lack of these associations suggests that the hypothesis that erythrocytes are engulfed in the shell gland and their heme is converted to eggshell pigments is less likely. In addition, we found no associations between female feces biliverdin concentration during egg laying and intensity of eggshell blue-green pigmentation, suggesting that eggshell biliverdin may not originate from biliverdin produced in the spleen or liver. Furthermore, we found no significant connections between the change in plasma and feces pigment levels between the prelaying and laying periods and the intensity of eggshell blue-green and brown pigmentations. This result also suggests that eggshell pigments are not derived from the circulation. Thus, our data suggest that biliverdin is synthesized de novo in the cells of the shell gland in the canary, similarly as proposed for poultry (Zhao et al. 2006; Wang et al. 2009, 2011).

Moreno and Osorno (2003) suggested that female birds may compromise their antioxidant capacity by depositing biliverdin, a potent antioxidant, into the eggshell. According to the SSEC hypothesis (Moreno and Osorno 2003), only females with good antioxidant capacity could afford to allocate high levels of biliverdin into the eggshell, and thus they signal their good quality to their mate so that he increases his parental care (Moreno et al. 2006; Soler et al. 2008; English and Montgomerie 2011). In this study, we found no evidence that eggshell biliverdin could be derived from the circulation, but our study together with some previous work on poultry (Zhao et al. 2006; Wang et al. 2009, 2011) suggests that the shell gland is the most likely site of biliverdin synthesis. In this case, the question arises as to how eggshell biliverdin concentration could signal female quality and condition. There may be several possibilities.

For instance, estrogen and progesterone were shown to increase the accumulation of pigments in the shell gland (Yamada 1972; Soh and Koga 1994, 1997), and prostaglandin could induce secretion of pigments in the shell gland (Soh and Koga 1999). It is possible that the synthesis and secretion of these hormones are affected by the general condition and oxidative status of the female bird, as steroid hormones may elevate the oxidative stress level (Dabrosin et al. 1998; von Schantz et al. 1999; Wassman et al. 2005). Furthermore,

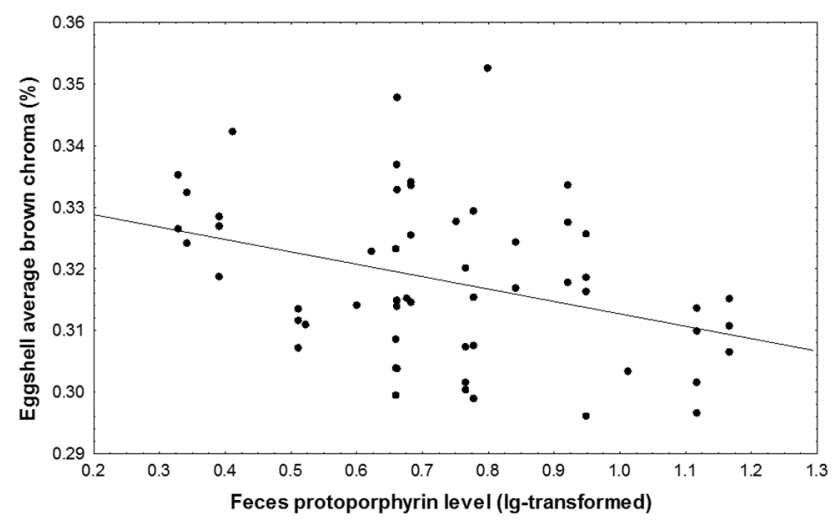

Figure 3. Relationship between female feces protoporphyrin concentration $(\mu \mathrm{g} / \mathrm{g}$; lg-transformed) during egg laying and eggshell average brown chroma in the canary $(R=-0.57, P=0.008)$. 
the gene expressions of carrier proteins that export pigments out of the cell membranes (e.g., ABCG2 in the case of protoporphyrin; Samiullah et al. 2015) may be affected by factors related to the condition of the female bird. In addition, the gene expression and the synthesis and activity of enzymes and proteins related to the molecular conversions in the pigment synthesis pathway may be influenced by the condition and oxidative status of the female bird or may have some oxidative costs (e.g., by inhibiting genes connected to antioxidant defense), which may limit the pigment synthesis of females of lower quality.

In the catabolism of heme to biliverdin, $\mathrm{HO}$ is the ratelimiting enzyme (Maines 1988; Murray 2003; Kikuchi et al. 2005). HO is suggested to function to protect the cells against oxidative damage by reducing the amount of heme and protoporphyrin and increasing the amount of biliverdin (Stocker 1990; Choi and Alam 1996; Morse and Choi 2002). Prooxidants may stimulate $\mathrm{HO}$ gene expression and thus increase the degradation of heme to biliverdin (Choi and Alam 1996; Schipper 2004). Moreover, erythrocyte degradation can be increased in oxidative stress and energy depletion (Lang et al. 2012). These findings suggest that females with a higher level of oxidative stress and a lower level of energy would generate a higher amount of biliverdin. However, an opposite pattern was usually observed for eggshell biliverdin, as female birds in better condition and with better antioxidant capacity laid eggs with more intense blue-green coloration (Moreno et al. 2006; Siefferman et al. 2006; Morales et al. 2011; Butler and McGraw 2013; Hargitai et al. 2016a). If circulating biliverdin, which is produced mainly in the spleen (Murray 2003), inhibits by some negative feedback mechanism the production of biliverdin in the cells of the shell gland, it could provide a possible explanation for the effect of antioxidant availability and body condition on eggshell blue-green color intensity. Further studies are necessary to test this hypothesis.

For protoporphyrin pigment, we found no significant positive associations between plasma protoporphyrin level, feces protoporphyrin level, polychromatophil percentage during egg laying, and the intensity of brown eggshell pigmentation. Therefore, we consider it less likely that eggshell protoporphyrin pigment is synthesized in the liver or in immature erythrocytes. Similarly, in the great tit, polychromatophil percentage had no significant effect on the protoporphyrin-based eggshell pigmentation (De Coster et al. 2012). However, we found significant negative associations of plasma and feces protoporphyrin concentrations during egg laying with the intensity of eggshell brown pigmentation. This result suggests that an increased production of protoporphyrin in the liver, which could have elevated plasma and feces protoporphyrin concentrations (Langer et al. 1972; Piomelli et al. 1975), could inhibit eggshell protoporphyrin pigmentation. Increased levels of plasma and feces protoporphyrin could primarily be due to limitation in iron or presence of toxic metals or infections (Langer et al. 1972; Piomelli et al. 1975; Casini et al. 2003). A higher level of protoporphyrin in the circulation may have inhibited the activity of enzymes in the synthesis pathway of protoporphyrin in the shell gland, similarly as heme inhibits the activity of ALA synthase (Murray 2003), or it may have stimulated ferrochelatase enzyme activity in the shell gland, thus converting protoporphyrin into heme. It might also be possible that there was a negative relationship between feces protoporphyrin concentration and intensity of eggshell brown pigmentation because the remaining pigments in the uterus fluid were excreted with feces. Further investigations are needed to examine these hypotheses.

De Coster et al. (2012) reported that in great tits the withinclutch increase in eggshell brown spot darkness was attenuated in clutches laid by females with higher bloodsucking ectoparasite abundance, suggesting that mature red blood cells could be important sources for eggshell protoporphyrin pigmentation. In contrast, based on our results, we suggest that increased anemia could act through elevating protoporphyrin production in the liver and thereby increasing the plasma protoporphyrin level, which may negatively affect the synthesis of protoporphyrin in the shell gland and thus decrease eggshell brown coloration. Hence, our results are in concordance with those of De Coster et al. (2012), although we propose a different explanation. We suggest that both pigments are produced in the shell gland, but the plasma level of pigments may inhibit shell gland pigment synthesis, thus connecting the physiological status of the female to eggshell coloration. Further studies are needed to investigate how circulating pigment levels could influence the pigment synthesis process in the shell gland and how this process could be connected to maternal condition and oxidative status.

Our results suggest that eggshell biliverdin and protoporphyrin pigments are synthesized de novo in the shell gland and not derived from the circulation, which is similar to the results found in poultry (Zhao et al. 2006; Wang et al. 2009, 2011). Thus, we may hypothesize that it is a common trait in bird species, although more studies including birds of different families and egg characteristics are needed to generalize these findings. We encourage more research in this respect with more avian species from different evolutionary lineages. In our study, we did not sacrifice animals, but a study investigating the pigment concentrations, level of gene expressions, and activity of relevant enzymes within the shell gland of reproducing birds of different species would further broaden our knowledge of the process of eggshell pigmentation. The origin of eggshell pigments may also determine which genes could be under selection in the evolution of eggshell coloration. Moreover, our data may have implications on how brood parasites evolved a mimetic eggshell coloration (Davies 2000), suggesting that the pigment synthesis activity of their shell glands, which probably became similar to that of the host species, could be under selective pressure. The broader ecological relevance of the study includes the idea that if avian eggshell pigments are produced in the shell gland, then any hypothesis concerning the possible costs, influential factors, and evolutionary processes of eggshell coloration should take this finding into consideration to avoid false conclusions.

Ancestral eggs were most probably white and immaculate (Kilner 2006), but today eggshell color is present in several bird families, implying that it has some adaptive value. The 
nature of the selective agent could be multiple (predators, brood parasites, exposure to direct sunlight, low availability of calcium, need for male parental care; Kilner 2006; Reynolds et al. 2009; Maurer et al. 2011) and could be affected by the ecology and behavior of the given species. Studies investigating how environmental, social, and physiological traits and phylogenetic origin may influence the pigment-producing activity of the shell gland should also be important to gain knowledge on the proximate causes of inter- and intraspecific variation in avian eggshell pigmentation. We believe that our results may trigger further studies that may expand our understanding of the mechanisms determining avian eggshell coloration.

\section{Acknowledgements}

We are grateful to B. Puskás-Farkas, A. Simões Souza, and G. Dri for help in the animal care. We are indebted to Zs. Eke and Z. Bodai for help in the development of the methods of pigment analysis. We thank I. Orbán for help in the eggshell pigment concentration analysis. We thank the handling editor and three anonymous reviewers for the constructive and helpful comments. This study was supported by the Hungarian Scientific Research Fund (OTKA; grant PD100304) and the Bolyai János Research Fellowship (MTA) to R.H. None of the funders had any input into the content of the manuscript. None of the funders required their approval of the manuscript before submission or publication. The authors declare that they have no conflict of interest. The National Food Chain Safety Office (NÉBIH) provided permissions for this study (PEI/001/824-4/2015). All applicable international, national, and institutional guidelines for the care and use of animals were followed.

\section{Literature Cited}

Afonso S., G. Vanore, and A. Batlle. 1999. Protoporphyrin IX and oxidative stress. Free Radic Res 31:161-170.

Baird T., S.E. Solomon, and D.R. Tedstone. 1975. Localisation and characterisation of egg shell porphyrins in several avian species. Br Poult Sci 16:201-208.

Bakken G.S., V.C. Vanderbilt, W.A. Buttemer, and W.R. Dawson. 1978. Avian eggs: thermoregulatory value of very high near-infrared reflectance. Science 200:321-323.

Board R.G. and N.H.C. Sparks. 1991. Shell structure and formation in avian eggs. Pp. 71-86 in D.C. Deeming and M.W.J. Ferguson, eds. Egg incubation: its effect on embryonic development in birds and reptiles. Cambridge University Press, Cambridge.

Butler M.W. and K.J. McGraw. 2013. Eggshell coloration reflects both yolk characteristics and dietary carotenoid history of female mallards. Funct Ecol 27:1176-1185.

Campbell T.W. and C.K. Ellis. 2013. Avian and exotic animal hematology and cytology. Blackwell, Aimes, IA.
Casini S., M.C. Fossi, C. Leonzio, and A. Renzoni. 2003. Review: porphyrins as biomarkers for hazard assessment of bird populations: destructive and non-destructive use. Ecotoxicology 12:297-305.

Choi A.M. and J. Alam. 1996. Heme oxygenase-1: function, regulation, and implication of a novel stress-inducible protein in oxidant-induced lung injury. Am J Respir Cell Mol Biol 15:9-19.

Collins E.C. 1993. Inheritance of egg-color polymorphism in the village weaver (Ploceus cucullatus). Auk 110:683-692.

Costantini D. 2016. Oxidative stress ecology and the d-ROMs test: facts, misfacts and an appraisal of a decade's work. Behav Ecol Sociobiol 70:809-820.

Dabrosin C., C. Hammar, and K. Ollinger. 1998. Impact of oestradiol and progesterone on antioxidant activity in normal human breast epithelial cells in culture. Free Rad Res 28: 241-249.

Davies N.B. 2000. Cuckoos, cowbirds and other cheats. Poyser, London.

De Coster G., L. De Neve, and L. Lens. 2012. Intraclutch variation in avian eggshell pigmentation: the anaemia hypothesis. Oecologia 170:297-304.

Duval C., P. Cassey, I. Mikšík, S.J. Reynolds, and K.A. Spencer. 2013. Condition-dependent strategies of eggshell pigmentation: an experimental study of Japanese quail (Coturnix coturnix japonica). J Exp Biol 216:700-708.

English P.A. and R. Montgomerie. 2011. Robin's egg blue: does egg color influence male parental care? Behav Ecol Sociobiol 65:1029-1036.

Fargallo J.A., I. López-Rull, I. Mikšík, A. Eckhardt, and J.M. Peralta-Sánchez. 2014. Eggshell pigmentation has no evident effects on offspring viability in common kestrels. Evol Ecol 28:627-637.

Fernandez F.R. and C.B. Grindem. 2006. Reticulocyte response. Pp. 110-116 in B.F. Feldman, J.G. Zinkl, and N.C. Jain, eds. Schalm's veterinary hematology. Blackwell, Ames, IA.

García-Navas V., J.J. Sanz, S. Merino, J. Martínez-de la Puente, E. Lobato, S. del Cerro, J. Rivero, R. Ruiz de Castañeda, and J. Moreno. 2010. Experimental evidence for the role of calcium in eggshell pigmentation pattern and breeding performance in blue tits Cyanistes caeruleus. J Ornithol 152: 71-82.

Gorchein A., C.K. Lim, and P. Cassey. 2009. Extraction and analysis of colourful eggshell pigments using HPLC and HPLC/electrospray ionization tandem mass spectrometry. Biomed Chromat 23:602-606.

Gosler A.G., P.R. Barnett, and S.J. Reynolds. 2000. Inheritance and variation in eggshell patterning in the great tit Parus. Proc R Soc B 267:2469-2473.

Gosler A.G., J.P. Higham, and S.J. Reynolds. 2005. Why are birds' eggs speckled? Ecol Lett 8:1105-1113.

Hackett S.J., R.T. Kimball, S. Reddy, R.C. Bowie, E.L. Braun, M.J. Braun, J.L. Chojnowski, et al. 2008. A phylogenomic study of birds reveals their evolutionary history. Science 320:1763-1768. 
Halliwell B. and J.M.C. Gutteridge. 2007. Free radicals in biology and medicine. Oxford University Press, Oxford.

Hargitai R., N. Boross, Z. Nyiri, and Zs. Eke. 2016a. Biliverdinand protoporphirin-based eggshell pigmentation in relation to antioxidant supplementation, female characteristics and egg traits in the canary (Serinus canaria). Behav Ecol Sociobiol 70:2093-2110.

Hargitai R., G. Nagy, M. Herényi, Z. Nyiri, M. Laczi, G. Hegyi, Zs. Eke, and J. Török. 2016b. Darker eggshell spotting indicates lower yolk antioxidant level and poorer female quality in the great tit (Parus major). Auk 133:131-146.

Hargitai R., G. Nagy, M. Herényi, and J. Török. 2013. Effects of experimental calcium availability, egg parameters, and laying order on great tit Parus major eggshell pigmentation patterns. Ibis 155:561-570.

Hargitai R., Z. Nyiri, Zs. Eke, and J. Török. 2016c. Effects of temperature and duration of storage on the stability of antioxidant compounds in egg yolk and plasma. Physiol Biochem Zool 89:161-167.

Hegyi G. and M. Laczi. 2015. Using full models, stepwise regression and model selection in ecological data sets: Monte Carlo simulations. Ann Zool Fenn 52:257-279.

Iamele L., R. Fiocchi, and A. Vernocchi. 2002. Evaluation of an automated spectrophotometric assay for reactive oxygen metabolites in serum. Clin Chem Lab Med 40:673-676.

Ishikawa S.I., K. Suzuki, E. Fukuda, K. Arihara, Y. Yamamoto, T. Mukai, and M. Itoh. 2010. Photodynamic antimicrobial activity of avian eggshell pigments. FEBS Lett 584:770774.

Johnsen A., K. Delhey, S. Andersson, and B. Kempenaers. 2003. Plumage colour in nestling blue tits: sexual dichromatism, condition dependence and genetic effects. Proc $\mathrm{R}$ Soc B 270:1263-1270.

Kaur H., M.N. Hughes, C.J. Green, P. Naughton, R. Foresti, and R. Motterlini. 2003. Interactions of bilirubin and biliverdin with reactive nitrogen species. FEBS Lett 543:113119.

Kennedy G.Y. and H.G. Vevers. 1973. Eggshell pigments of the Araucano fowl. Comp Biochem Physiol B 44:11-25.

- 1976. A survey of avian eggshell pigments. Comp Biochem Physiol B 55:117-123.

Kikuchi G., T. Yoshida, and M. Noguchi. 2005. Heme oxygenase and heme degradation. Biochem Biophys Res Comm 338:558-567.

Kilner R.M. 2006. The evolution of egg colour and patterning in birds. Biol Rev 81:383-406.

König K. and H. Meyer. 1992. Photodynamically induced inactivation of propionibacterium acnes using the photosensitizer methylene blue and red light. Dermatol Monatsschr 178: 297-300.

Lamola A.A., I. Asher, U. Muller-Eberhard, and M. PohFitzpatrick. 1981. Fluorimetric study of the binding of protoporphyrin to haemopexin and albumin. Biochem J 196:693-698.

Lang F., E. Lang, and M. Föller. 2012. Physiology and pathophysiology of eryptosis. Transfus Med Hemother 39:308-314.
Langer E.E., R.G. Haining, R.F. Labbe, P. Jacobs, E.F. Crosby, and C.A. Finch. 1972. Erythrocyte protoporphyrin. Blood 40:112-128.

Lessells C.M. and P.T. Boag. 1987. Unrepeatable repeatabilities: a common mistake. Auk 104:116-121.

Liu H.C., M.C. Hsiao, Y.H. Hu, S.R. Lee, and W.T.K. Cheng. 2010. Eggshell pigmentation study in blue-shelled and whiteshelled ducks. Asian Australas J Anim Sci 23:162-168.

Lovell P.G., G.D. Ruxton, K.V. Langridge, and K.A. Spencer. 2013. Egg-laying substrate selection for optimal camouflage by quail. Curr Biol 23:260-264.

Maines M.D. 1988. Heme oxygenase: function, multiplicity, regulatory mechanisms, and clinical applications. FASEB J 2:2557-2568.

Martínez-de la Puente J., S. Merino, J. Moreno, G. Tomás, J. Morales, E. Lobato, S. García-Fraile, and J. Martínez. 2007. Are eggshell spottiness and colour indicators of health and condition in blue tits Cyanistes caeruleus? J Avian Biol 38: 377-384.

Maurer G., S.J. Portugal, and P. Cassey. 2011. Review: an embryo's eye view of avian eggshell pigmentation. J Avian Biol 42:494-504.

Maurer G., S.J. Portugal, M.E. Hauber, I. Mikšík, D.G. Russell, and P. Cassey. 2015. First light for avian embryos: eggshell thickness and pigmentation mediate variation in development and UV exposure in wild bird eggs. Funct Ecol 29: 209-218.

McDonagh A.F. 2001. Turning green to gold. Nat Struct Mol Biol 8:198-200.

McNeil K.A., I. Newman, and F.J. Kelly. 1996. Testing research hypotheses with the general linear model. Southern Illinois University Press, Carbondale.

Mikšík I., V. Holáň, and Z. Deyl. 1996. Avian eggshell pigments and their variability. Comp Biochem Physiol B 113: 607-612.

Morales J., S.Y. Kim, E. Lobato, S. Merino, G. Tomás, J. Martínez-de la Puente, and J. Moreno. 2010. On the heritability of blue-green eggshell coloration. J Evol Biol 23: 1783-1791.

Morales J., A. Velando, and R. Torres. 2011. Biliverdin-based egg coloration is enhanced by carotenoid supplementation. Behav Ecol Sociobiol 65:197-203.

Moreno J., E. Lobato, J. Morales, S. Merino, G. Tomás, J. Martínez-de la Puente, J.J. Sanz, R. Mateo, and J.J. Soler. 2006. Experimental evidence that egg color indicates female condition at laying in a songbird. Behav Ecol 17:651-655.

Moreno J. and J.L. Osorno. 2003. Avian egg colour and sexual selection: does eggshell pigmentation reflect female condition and genetic quality? Ecol Lett 6:803-806.

Morse D. and A.M. Choi. 2002. Heme oxygenase-1: the "emerging molecule" has arrived. Am J Respir Cell Mol Biol 27:8-16.

Moskát C., J.M. Avilés, M. Bán, R. Hargitai, and A. Zölei. 2008. Experimental support for the use of egg uniformity in parasite egg discrimination by cuckoo hosts. Behav Ecol Sociobiol 62: 1885-1890. 
Murray R.K. 2003. Porphyrins and bile pigments. Pp. 270-285 in R.K. Murray, D.K. Granner, P.A. Mayes, and V.W. Rodwell, eds. McGraw-Hill, New York.

Oniki Y. 1979. Nest-egg combinations: possible antipredatory adaptations in Amazonian birds. Rev Bras Biol 39:747-767.

Peters A., K. Delhey, S. Andersson, H. Van Noordwijk, and M.I. Förschler. 2008. Condition-dependence of multiple carotenoid-based plumage traits: an experimental study. Funct Ecol 22:831-839.

Pimentel E., L.M. Vidal, M.P. Cruces, and M.K. Janczur. 2013. Action of protoporphyrin-IX (PP-IX) in the lifespan of Drosophila melanogaster deficient in endogenous antioxidants, SOD and CAT. Open J Anim Sci 3:1-7.

Piomelli S., A.A. Lamola, M.B. Poh-Fitzpatrick, C. Seaman, and L.C. Harber. 1975. Erythropoietic protoporphyria and lead intoxication: the molecular basis for difference in cutaneous photosensitivity. I. Different rates of disappearance of protoporphyrin from the erythrocytes, both in vivo and in vitro. J Clin Invest 56:1519-1527.

Polin D. 1957. Formation of porphyrin from deltaaminolevulenic acid by uterine and liver tissue from laying hens. Exp Biol Med 94:276-279.

Poole H.K. 1967. A microscopic study of uterine eggshell pigment in Japanese quail. J Hered 58:200-203.

Reynolds S.J., G.R. Martin, and P. Cassey. 2009. Is sexual selection blurring the functional significance of eggshell coloration hypotheses? Anim Behav 78:209-215.

Samiullah S., J.R. Roberts, and K. Chousalkar. 2015. Eggshell color in brown-egg laying hens - a review. Poult Sci 94:25662575.

Schipper H.M. 2004. Heme oxygenase-1: transducer of pathological brain iron sequestration under oxidative stress. Ann NY Acad Sci 1012:84-93.

Schwartz S., W.A. Raux, B.A. Schacter, B.D. Stephenson, and R.N. Shoffner. 1980. Loss of hereditary uterine protoporphyria through chromosomal rearrangement in mutant Rhode Island red hens. Int J Biochem 12:935-940.

Siefferman L., K.J. Navara, and G.E. Hill. 2006. Egg coloration is correlated with female condition in eastern bluebirds (Sialia sialis). Behav Ecol Sociobiol 59:651-656.

Singleton J.W. and L. Laster. 1965. Biliverdin reductase of guinea pig liver. J Biol Chem 240:4780-4789.

Soh T., N. Fujihara, and O. Koga. 1993. Observations of pigment accumulation in the epithelium of the shell gland and superficial pigmentation on the egg shell in Japanese quail. J Fac Agric Kyushu Univ 38:73-80.

Soh T. and O. Koga. 1994. The effects of sex steroid hormones on the pigment accumulation in the shell gland of Japanese quail. Poult Sci 73:179-185.

- 1997. The effect of progesterone and estradiol-17beta on the pigment accumulation of the shell gland in Japanese quail pretreated with aminoglutethimide. J Fac Agric Kyushu Univ 42:147-150.

. 1999. The sensitivity of the shell gland to prostaglandin in quail; on the secretion of pigment from the mucous epithelium. Anim Sci J 70:170-173.
Soler J.J., C. Navarro, T.P. Contreras, J.M. Avilés, and J.J. Cuervo. 2008. Sexually selected egg coloration in spotless starlings. Am Nat 171:183-194.

Soler J.J., M. Soler, and A.P. Møller. 2000. Host recognition of parasite eggs and the physical appearance of host eggs: the magpie and its brood parasite the great spotted cuckoo. Etología 8:9-16.

Stevens E.V., L.K. Miller, S. Weinstein, and A. Kappas. 1974. Biosynthesis of $\delta$-aminolevulinic acid and porphobilinogen in the domestic fowl (Gallus domesticus). Comp Biochem Physiol B 47:779-786.

Stocker R. 1990. Induction of haem oxygenase as a defence against oxidative stress. Free Rad Res Comm 9:101-112.

Stocker R., Y. Yamamaoto, A.F. McDonagh, A.N. Glazer, and B.N. Ames. 1987. Bilirubin as an antioxidant of possible physiological importance. Science 235:1043-1046.

Stoddard M.C., A.L. Fayet, R.M. Kilner, and C.A. Hinde. 2012. Egg speckling patterns do not advertise offspring quality or influence male provisioning in great tits. PLoS ONE 7:e40211.

Stoddard M.C., K.L.A. Marshall, and R.M. Kilner. 2011. Imperfectly camouflaged avian eggs: artefact or adaptation? Avian Biol Res 4:196-213.

Stokke B.G., A. Moksnes, E. Røskaft, G. Rudolfsen, and M. Honza. 1999. Rejection of artificial cuckoo (Cuculus canorus) eggs in relation to variation in egg appearance among reed warblers (Acrocephalus scirpaceus). Proc R Soc Lond B 266: 1483-1488.

von Schantz T., S. Bensch, M. Grahn, D. Hasselquist, and H. Wittzell. 1999. Good genes, oxidative stress and conditiondependent sexual signals. Proc R Soc B 266:1-12.

Wagner E.C., J.S. Prevolsek, K.E. Wynne-Edwards, and T.D. Williams. 2008a. Hematological changes associated with egg production: estrogen dependence and repeatability. J Exp Biol 211:400-408.

Wagner E.C., C.A. Stables, and T.D. Williams. 2008b. Hematological changes associated with egg production: direct evidence for changes in erythropoiesis but a lack of resource dependence? J Exp Biol 211:2960-2968.

Wang X.T., C.J. Zhao, J.Y. Li, G.Y. Xu, L.S. Lian, C.X. Wu, and X.M. Deng. 2009. Comparison of the total amount of eggshell pigments in Dongxiang brown-shelled eggs and Dongxiang blue-shelled eggs. Poult Sci 88:1735-1739.

Wang Z.P., R.F. Liu, and A.R. Wang. 2013. Comparison of HMOX1 expression and enzyme activity in blue-shelled chickens and brown-shelled chickens. Genet Mol Biol 36:282-286.

Wang Z.P., R.F. Liu, A.R. Wang, J.Y. Li, and X.M. Deng. 2011. Expression and activity analysis reveal that heme oxygenase (decycling) 1 is associated with blue egg formation. Poult Sci 90:836-841.

Wassmann K., S. Wassmann, and G. Nickenig. 2005. Progesterone antagonizes the vasoprotective effect of estrogen on antioxidant enzyme expression and function. Circ Res 97:1046-1054.

Westmoreland D., M. Schmitz, and K.E. Burns. 2007. Egg color as an adaptation for thermoregulation. J Field Ornithol 78:176-183.

Willie J., M. Travers, and T.D. Williams. 2010. Female zebra finches (Taeniopygia guttata) are chronically but not cu- 
mulatively "anemic" during repeated egg laying in response to experimental nest predation. Physiol Biochem Zool 83: 119-126.

Yamada M. 1972. $\sigma$-aminolevulinic acid dehydratases from shell gland and liver of Japanese quail, Coturnix coturnix japonica. I. Purification, properties and hormonal induction. Biochim Biophys Acta 279:535-543.

Zhao R., G.Y. Xu, Z.Z. Liu, J.Y. Li, and N. Yang. 2006. A study on eggshell pigmentation: biliverdin in blue-shelled chickens. Poult Sci 85:546-549. 